\title{
Evaluation of an effective and cheap analgesic protocol prior to intra-uterine device insertion in a developing country
}

\author{
Jai Bhagwan Sharma*, Mukta Agarwal, Debjyoti Karmakar, Sunesh Kumar
}

Department of Obstetrics and Gynaecology; All India Institute of Medical Sciences, New Delhi, India

Received: 23 May 2015

Accepted: 06 June 2015

\author{
*Correspondence: \\ Dr. Jai Bhagwan Sharma, \\ E-mail: jbsharma2000@gmail.com
}

Copyright: () the author(s), publisher and licensee Medip Academy. This is an open-access article distributed under the terms of the Creative Commons Attribution Non-Commercial License, which permits unrestricted non-commercial use, distribution, and reproduction in any medium, provided the original work is properly cited.

\begin{abstract}
Background: Intrauterine (contraceptive) device (IUD) insertion is a common outpatient gynecologic procedure. This study aimed to evaluate the effect of premedication with oral drotaverine-mefenamic acid on pain perception during IUD insertion.

Methods: Double blinded placebo controlled randomized trial involving fifty six women undergoing IUD insertion in outpatient clinic, randomized into 2 groups. Group I $(n=31)$ received tablet containing drotaverine hydrochloride $(80$ $\mathrm{mg})+$ mefenamic acid $(250 \mathrm{mg})$, group II $(\mathrm{n}=25)$ received placebo. The intensity of pain during the procedure, 15 and 30 minutes later was assessed on visual analog scale (VAS). Kruskal-Wallis test, with the Bonferroni correction, the $t$ test, analysis of variance (ANOVA) and the $\chi 2$ test were used for statistical analysis.

Results: Groups were similar demographically. A significant difference in pain scores was noted among the 2 groups during the procedure (group I, 2.32 \pm 1.137 ; group II, $4.32 \pm 1.676(P=0.001)$, 15 minutes later (group I, 1.28 \pm 0.59 ;

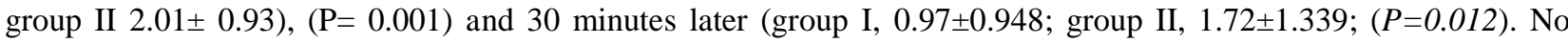
significant adverse effects were observed. A post hoc analysis revealed adequate power.

Conclusions: Oral drotaverine-mefenamic acid provides a cheap option for effective analgesia prior to IUD insertion in clinic.
\end{abstract}

Keywords: Randomized trial, Intrauterine device (IUD), Pain, Premedication

\section{INTRODUCTION}

Intrauterine (contraceptive) device (IUD) insertion is one of the most common outpatient procedures in gynecologic practice. Previously, this procedure was done without analgesia. ${ }^{1}$ Schoenfeld et al. and Kajve et al. concluded that intravenous diazepam and pentazocine is effective for pain relief during minor gynecological operations and tubal ligation. ${ }^{2,3}$ With the advent of locally acting better drugs, many centers stopped using intravenous sedation in view of safety concerns and narrow therapeutic window. Various methods of local anesthesia including paracervical block have been studied to reduce the pain but the evidence on efficacy is still not strong. ${ }^{4-6}$ Additionally techniques involving manipulation of cervix, like introduction of IUD, hysteroscope, result in increased pain due to prostaglandin release. Therefore, it seems logical to prime the cervix and use prostaglandin synthesis inhibitors prophylactically before the procedure. Drotaverine hydrochloride, an isoquinoline derivative, is a potent spasmolytic widely used in biliary and renal colic, for augmentation of labor, dysmenorrhea and before instrumental diagnostic procedures. It acts directly on the smooth muscles by inhibiting phosphodiesterase activity and is devoid of any anticholinergic side effects. ${ }^{7-10}$ Mefenamic acid, a nonsteroidal anti-inflammatory drug, is widely used in gynecology to treat dysmenorrhea and menorrhagia which inhibits cyclooxygenase enzyme and exerts its anti-inflammatory and analgesic action by inhibiting prostaglandin synthesis. Thus, a relatively cheap fixed dose combination of drotaverine hydrochloride with 
mefenamic acid would be expected to reduce the discomfort of the IUD insertion in a synergistic fashion.

We tested this hypothesis by studying the efficacy of fixed-dose (oral) combination of drotaverine $(80 \mathrm{mg}$ ) with mefenamic acid $(250 \mathrm{mg})$ on pain perception during IUD insertion and compared it with that of placebo. ]. A lot of clinic based studies have focused on outpatient hysteroscopy and analgesic protocols in same, however there are a paucity of similar studies on Indian women and specifically for IUD insertion.

\section{METHODS}

This Randomized Placebo Controlled Double Blinded Trial was conducted between January 2009 and July 2009 in the Gynecology department of All India Institute of Medical Sciences, New Delhi, India. The Ethics Committee of the institute approved the study (Ethical clearance reference number: P-4/12-1, dated 12.01.2009). While calculating required sample size for each group it was presumed at the time of IUD insertion the average VAS score and standard deviation would be 2.0 and 1.5 respectively for group $\mathrm{A}$. The corresponding values for group B were presumed to be 3.0 and 1.5. Expecting $95 \%$ confidence with $80 \%$ power a sample size of 36 was arrived using statistical software STATA version 10.0. A total of 56 women with a medical indication for IUD insertion were recruited. Informed written consent for the intervention was taken from all. The patients were informed about details of the study in their language before taking their written consent. The contraceptive IUD used in all cases was CuT (copper T) 380A as per national protocol.

The criteria for exclusion from the study were:

(1) Pregnancy;

(2) Having a known sensitivity to nonsteroidal antiinflammatory drugs, lignocaine; (3) Having peptic ulcer disease, inflammatory bowel disease, porphyrias, genital infections, undiagnosed vaginal bleeding cervical stenosis, serious cardiac disease;

(3) Being unable or unwilling to provide informed consent; and

(4) Having history of cervical surgery.

This study was a double blinded randomized trial where all the 56 patients were randomized using a predetermined computer generated randomization code into 2 groups (Figure 1). Group I $(n=31)$ patients received fixed-dose oral tablet containing drotaverine $(80 \mathrm{mg}$ ) with mefenamic acid $(250 \mathrm{mg})$. Group II patients $(\mathrm{n}=25)$ received placebo. Both groups received the drug half an hour before insertion. In this study, the procedure was performed by the same resident gynecologist throughout the study period who did not know the group to which the patient belonged. The outcome measure (pain score) was evaluated by a resident doctor throughout the study who did not know the treatment protocol.. Women in all the groups were placed in dorsal position and bimanual examination was done. After cleaning and draping, a bivalved speculum was inserted to expose the cervix; the anterior lip of cervix was grasped with tenaculum .If cervical dilatation was required, it was performed and noted.

The resident doctor evaluating the outcome measure asked the patients to score the worst pain experienced during the procedure and the degree of their discomfort after 15 minutes and 30 minutes of the procedure using a 10-cm line visual analog scale (VAS: $0 \mathrm{~cm}$ - no pain, 10 $\mathrm{cm}$ - excruciating pain). No further follow up was scheduled from the point of view of this study. They, however had the usual follow-up as part of protocol of the family planning clinic for all IUD insertions, where each woman was asked to revisit after next menses to get the thread checked or to report if excessive pain, offensive vaginal discharge, fever, nausea/vomiting, excessive vaginal bleeding or expulsion of IUD was noted. No woman was excluded and the procedure was not abandoned at any point of time after recruiting.

\section{Statistical Analysis}

Mean age of study subjects between two groups was compared using Student's ' $t$ ' independent test. Distribution of subjects by parity condition, menstrual cycle and time since last delivery was compared between two groups using chi-square test. Since VAS was assessed repeatedly at different time points (prior, during, 30 minutes, 120 minutes, 24 hours and 48 hours) for each subject repeated measures analysis of variance (ANOVA) was used. While carrying out this analysis drug group was taken as factor and base-line characteristics of subjects (age, parity, menstruation cycle and time since last delivery) were taken as covariates to rule out confounding effect. Pair wise comparison of mean scores was done with Bonferroni correction. For all the tests $P<0.05$ was considered for statistical significances and STATA software version 10.0 was used for analysis.

\section{RESULTS}

The characteristics of patients are given in Table 1. 56 patients recruited, procedure was performed successfully in all and at no point anyone was excluded from the study. All the data has been mentioned as mean \pm standard deviation, 95\% confidence interval (CI) for mean with lower and upper bound values. There was no statistical difference in age, parity, vaginal deliveries and indication for IUD among the two groups [Table 1]. The age ranged from 20 to 61 years. Parity ranged from 0 to 4 with mean being $1.48,1.40$ in groups I and II respectively. A statistically significant difference in pain scores was noted among the 2 groups during the procedure (group I, 2.32 \pm 1.137 ; group II, 4.32 $\pm 1.676(P=$ 0.001 ); as well as 15 minutes later (group I, 1.28 0.59; group II $2.01 \pm 0.93),(P=0.001)$ and 30 minutes later (group I, 0.97 \pm 0.948 ; group II, 1.72 \pm 1.339$)$, $(\mathrm{P}=0.012)$. 
VAS at different time intervals among the groups was also statistically significant [Table 2]. After adjusting for base-line characteristics repeated measures ANOVA with a Greenhouse-Geisser correction determined that the interaction effect of VAS at different time lags and drug groups was statistically significant $(\mathrm{F}(2.166$, 106.144) $=15.70 ; \quad P<0.001)$ and explained $24 \%$ of variance in VAS. Further, the interaction effect of VAS with base-line characteristics was not found to be statistically significant $(P>0.05)$ implying that severity of pain is independent of base-line characteristics. Test of between subjects effects revealed that there is a significant variation $(\mathrm{F}(1,49)=17.46 ; P<0.001)$ in VAS between groups and explained $26 \%$ in VAS. Comparison of estimated marginal mean VAS at different time points (Figure 1) showed that there is a significant reduction in mean VAS among Group A patients during $\mathrm{Cu} T$ insertion and 30 minutes after insertion compared to that of Group B patients.

Table 1: Comparisons of demographic characteristics between two groups.

\begin{tabular}{|c|c|c|c|}
\hline Characteristic & $\begin{array}{l}\text { Group-A } \\
(\mathrm{n}=\mathbf{3 1})\end{array}$ & $\begin{array}{l}\text { Group-B } \\
(n=25)\end{array}$ & P-value \\
\hline Age(yrs) & $27.77 \pm 5.29$ & $28.72 \pm 5.94$ & 0.532 \\
\hline $\begin{array}{l}\text { Parity Primipara } \\
\text { Multipara }\end{array}$ & $\begin{array}{l}13 \\
18\end{array}$ & $\begin{array}{l}7 \\
18\end{array}$ & 0.277 \\
\hline $\begin{array}{l}\text { Menstrual cycle } \\
\text { - Regular } \\
\text { - Irregular } \\
\text { - Lactational } \\
\text { amenorrhoea }\end{array}$ & $\begin{array}{c}22 \\
5 \\
4\end{array}$ & $\begin{array}{c}18 \\
5 \\
2\end{array}$ & 0.807 \\
\hline $\begin{array}{l}\text { Time since last } \\
\text { delivery } \\
<3 \text { yrs } \\
3-6 \text { yrs } \\
>6 \text { yrs }\end{array}$ & $\begin{array}{c}19 \\
4 \\
8\end{array}$ & $\begin{array}{c}12 \\
7 \\
6\end{array}$ & 0.356 \\
\hline
\end{tabular}

Table 2: Comparisons of median VAS score between two groups at different time interval.

\begin{tabular}{|lllll|}
\hline $\begin{array}{l}\text { Outcome } \\
\text { VAS-I } \\
\text { (prior to }\end{array}$ & mean \pm SD & $0.26 \pm 0.514$ & $0.20 \pm 0.408$ & \\
$\begin{array}{l}\text { IUD } \\
\text { insertion) }\end{array}$ & median & 0.00 & 0.00 & 0.663 \\
\hline $\begin{array}{l}\text { VAS-II } \\
\text { (at IUD }\end{array}$ & mean \pm SD & $2.32 \pm 1.137$ & $4.32 \pm 1.676$ & \\
insertion) & median & 2.00 & 4.00 & 0.001 \\
\hline $\begin{array}{l}\text { VAS-III } \\
(15 \text { mins }\end{array}$ & mean \pm SD & $1.28 \pm 0.59$ & $2.01 \pm 0.93$ & \\
$\begin{array}{l}\text { after } \\
\begin{array}{l}\text { IUD } \\
\text { insertion) }\end{array}\end{array}$ & median & 1 & 1 & 0.001 \\
\hline $\begin{array}{l}\text { VAS-IV } \\
(30 \text { mins }\end{array}$ & mean \pm SD & $0.97 \pm 0.948$ & $1.72 \pm 1.339$ & \\
$\begin{array}{l}\text { after } \\
\begin{array}{l}\text { IUD } \\
\text { insertion })\end{array}\end{array}$ & median & 1.00 & 1.00 & 0.012 \\
\hline
\end{tabular}

*Mann-Whitney test

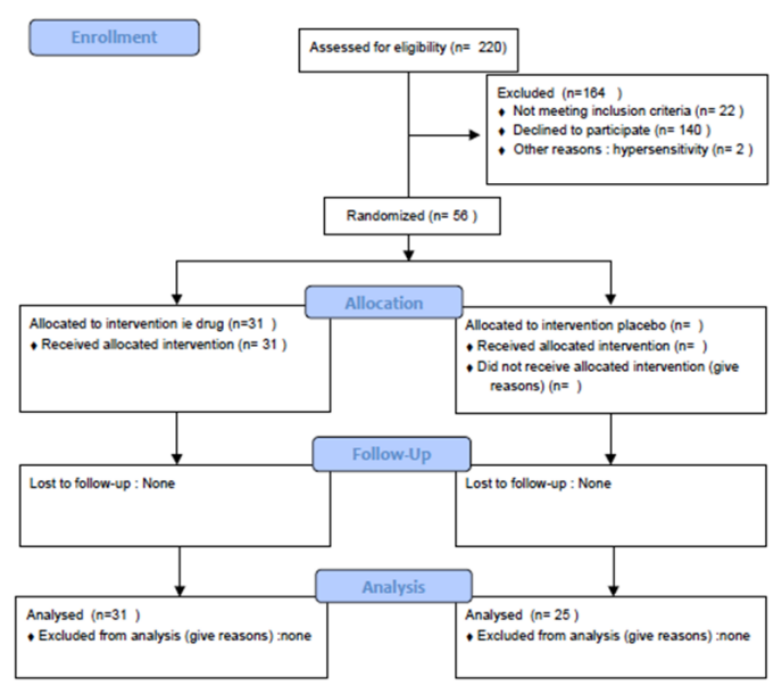

Figure 1: Consort flow diagram.

A post hoc analysis of VAS scores at the time of IUD insertion and at 15 mins was performed. The power of the study with these observations is $99 \%$. One patient in drotaverine with mefenamic acid group complained of gastritis after 2 hours of ingestion, 4 complained of abdominal cramps after 1 hour of the procedure and no other adverse effects were noted; whereas 12 patients in group II complained of abdominal cramps after 1 hour of the procedure.

\section{DISCUSSION}

A spasmolytic like drotaverine and anti-prostaglandin like mefenamic acid may be synergistically efficacious in analgesia in this setting as they have different mechanisms of action. Both are well absorbed orally. Peak plasma concentration of drotaverine is attained within 1 hour; and that of mefenamic acid, in 2 to 4 hours. The two molecules in a fixed-dose combination provide comprehensive pain relief. Drotaverine allays the early-onset pain and potentiates the sustained analgesic effect of mefenamic acid. As the special property of fixed dose combination having synergistic effects allows achieving relief in early-onset pain by drotaverine and sustained analgesic effect by mefenamic acid. The data from this study demonstrates that the combination of drotaverine and mefenamic acid is effective in decreasing the pain during the procedure and its effect lasts longer than that of paracervical block or intravenous sedation as available from contemporary literature. Various methods of local anesthesia have been studied to reduce the pain, and it was suggested that paracervical block, topical lignocaine, intracervical lignocaine may reduce the pain but the evidence is still not strong. ${ }^{4-6}$ Despite the use of local anesthesia and intravenous sedation, the commonest reason for failure to complete the procedure is pain. Pain perceived in the cervix and uterine corpus appears to pass through 2 distinct neural pathways. A paracervical block 
aids in decreasing pain from cervical origin, but the extent of its effect on pain related to uterine activity is unclear. Paracervical lignocaine was found to be ineffective in reducing pain during endometrial biopsy and also carried the risk of inducing bradycardia, hypotension, convulsion, respiratory arrest and death. ${ }^{5}$ In another randomized trial, Vercellini et al. demonstrated that paracervical block is ineffective in reducing the discomfort of hysteroscopy and noted that it is the endometrial biopsy which is the most painful part of the procedure. $^{6}$ Broadbent et al. demonstrated that intracervical injection of lignocaine does not reduce the pain during hysteroscopy. ${ }^{11}$ Fritz et al., in 1997, in a randomized double-blind placebo-controlled trial concluded that $500 \mathrm{mg}$ of mefenamic acid 1 hour before hysteroscopy had no significant effect on the discomfort experienced during the procedure but did significantly reduce pain after the procedure. ${ }^{12}$ In another placebo controlled trial, Dogan et al. showed that naproxen when combined with lidocaine was effective in relieving pain during endometrial biopsy. ${ }^{13}$ Drotaverine is effectively used in gynecological conditions like dysmenorrheal and nongynecological conditions like renal colic and cholelithiasis. ${ }^{8}$ In the studies by Sharma et al. and Singh et al., Drotaverine when used during labor was shown to accelerate the labor and no adverse effects were seen. ${ }^{9,10}$ In literature there are studies where plain NSAIDs were used for pain relief before minor gynecological procedures and compared subsided in the following few hours with placebo, paracervical block, intrauterine lignocaine insertion, local spray of lignocaine gel, but the results were not conclusive. ${ }^{12-14}$ A lot of clinic based studies have focused on outpatient hysteroscopy and analgesic protocols in same. Yang and Vollenhoven have reviewed pain control in outpatient hysteroscopy and failed to obtain substantial conclusive evidence for the routine use of local anesthesia in outpatient hysteroscopy. ${ }^{14}$ Various reasons have been cited for this, like cultural factors for pain tolerance, race, diameter of the hysteroscope, etc. ${ }^{15}$ There is a paucity of similar studies on Indian women, and specifically for IUD insertion. The present study is highly relevant in a developing country like India, where needles may be recycled putting the patient at risk of acquiring viral diseases. Moreover, the combination of mefenamic acid and drotaverine is an oral drug; is cheaper, costing Indian Rupees (INR) 2.00 (0.03 US dollars(USD) as of September 2013 ); less invasive than paracervical block (costing approximately INR 10.00-15.00; 0.16-0.24 USD as of September 2013) and intravenous sedation (costing approximately INR. 30.00-40.00;0.48-0.64 USD as of September 2013); and has got no major adverse effects. To our knowledge, this is the first study to evaluate the efficacy of oral drotaverine plus mefenamic acid for pain relief during office IUD insertion.

This study has a few limitations, such as the small number of patients; also, other secondary outcome measures like hemodynamic parameters like blood pressure, heart rate and time taken for the procedure have not been evaluated. However the prior sample size calculation, randomized methodology and placebo control, post hoc power validation are the strong points of this study. Since racial and cultural factors also contribute to the pain tolerance levels, large multi-centered placebocontrolled trials need to be done to prove the efficacy of oral drotaverine and mefenamic acid for gynecological office procedures to avoid beta error and arrive at level I evidence. To conclude, fixed dose combination of Oral drotaverine with mefenamic acid is a cheap and effective protocol in women undergoing IUD insertion in clinic.

\section{Disclosure of Conflict of Interest}

This study was approved by Institute Ethics Committee and all norms related to drug intervention trials were followed. Martin and Harris Private Ltd., India, supplied Drotin-M tablets as free physician samples and have had no influence on the study. The company or its representatives were in no way involved with the recruitment, administration including randomization, analysis and interpretation of results. They have not been informed about the results.

We do not have a financial relationship with the company that provided the free medications for the project. We have had full control of all primary data and we agree to allow the journal to review our data if requested.

\section{ACKNOWLEDGEMENTS}

We thank Martin and Harris Private Ltd., India, for supplying Drotin-M tablets free of cost.

\section{Funding: No funding sources Conflict of interest: Declared \\ Ethical approval: The study was approved by the Institutional Ethics Committee}

\section{REFERENCES}

1. Nagele F, O'Connor H, Davies A, Mohamed H, Magos A. 2500 Outpatient hysteroscopies. Obstet Gynecol. 1996;88:87-92.

2. Schoenfeld A, Goldmann JA, Levy E. Pentazocine and diazepam for minor gynaecological operations. Br J Anaesth. 1974;46:385-6.

3. Kajve PP, Sarate GS. Local infiltration block supplemented by diazepam and pentazocine combination for tubal ligation. J Indian Med Assoc. 1984;84:143-5.

4. De Jong P, Doel F, Falconer A. Outpatient diagnostic hysteroscopy. Br J Obstet Gynaecol. 1990;97:299303.

5. Lau WC, Lo WK, Tam WH, Yuen PM. Paracervical anaesthesia in outpatient hysteroscopy: A randomized double blind placebo controlled trial. $\mathrm{Br}$ J Obstet Gynaecol. 1999;106:356-9.

6. Vercellini P, Colombo A, Mauro F, Oldani S, Bramante T, Crosignani PG. Paracervical anesthesia 
for outpatient hysteroscopy. Fertil Steril. 1994;62: 1083-5.

7. Blasko G. Pharmocology: a mechanism of action and clinical signifi cance of a convenient antispasmodic agent: Drotaverine. J Am MedAssoc India. 1998;1:63-9.

8. Romics I, Molnar DL, Timberg G, Mrklic B, Jelakovic B, Koszegis G, et al. The effect of drotaverine hydrochloride in acute colicky pain caused by renal and ureteric stones. BJU Int. 2003;92:92-6.

9. Sharma JB, Pundir P, Kumar A, Murthy NS. Drotaverine hydrochloride Valethamate bromide in acceleration of labor. Int $\mathbf{J}$ Gynecol Obstet. 2001;4:43-8

10. Singh KC, Jain P, Goel N, Saxena A. Drotaverine hydrochloride for augmentation of labor. Int $\mathrm{J}$ Gynecol Obstet. 2004;84:17-22.

11. Broadbent JA, Hill NC, Molnar BG, Rolfe KJ, Magos AL. Randomized placebo controlled trial to assess the role of intracervical lignocaine in outpatient hysteroscopy. $\mathrm{Br} \mathrm{J}$ Obstet Gynecol. 1992;99:777-80.
12. Nagele F, Lockwood G, Magos AL. Randomized placebo controlled trial of mefenemic acid for premedication at outpatient hysteroscopy: A pilot study. Br J Obstet Gynaecol. 1997;104:842-4.

13. Dogan E, Celiloglu M, Sarihan E, Demir A. Anesthetic effect of intrauterine lidocaine plus naproxen sodium in endometrial biopsy. Obstet Gynecol. 2004;103:347-51.

14. Yang J, Vollenhoven B. Pain control in outpatient hysteroscopy. Obstet Gynecol Surv. 2002;57: 693702.

15. Cicinelli E, Rossi AC, Marinaccio M, Matteo M, Saliani N, Tinelli R. Predictive factors for pain experienced at office fluid minihysteroscopy. J Minim Invasive Gynecol. 2007;14:485-8.

Cite this article as: Sharma JB, Agarwal M, Karmakar D, Kumar S. Evaluation of an effective and cheap analgesic protocol prior to intra-uterine device insertion in a developing country. Int $\mathrm{J}$ Reprod Contracept Obstet Gynecol 2015;4:1061-5. 